\title{
Association of Autoantibody to Rods and Rings with Hepatitis C Outcome and Viral Load
}

\author{
Tarak Dhaouadi, ${ }^{1}$ Jihen Abdellatif,, Mariem Jallouli, ${ }^{1}$ Maroua Mejdoubi, ${ }^{1}$ Imen Sfar, \\ Leila Mouelhi, ${ }^{2}$ Saloua Aouini, ${ }^{1}$ Taïeb Ben Abdallah, ${ }^{1,3}$ and Yousr Gorgi ${ }^{1}$
}

\begin{abstract}
Despite the current availability of more potent drugs, hepatitis C virus (HCV) infection is still treated with a combination of IFN- $\alpha$ and ribavirin in many countries. Interferon/ribavirin therapy can induce the appearance of autoantibodies to Rods and Rings (anti-RR), which have been associated to a poorer prognosis. The aim of this study was to investigate the prevalence of anti-RR antibodies before and after ribavirin therapy and to look for a possible association with HCV infection outcome. In this context, anti-RR antibodies were detected by IFI on HEp- 2 cells in 142 patients under ribavirin therapy (G1: 74 patients with a positive posttreatment HCV-PCR and G2: 68 patients with a negative posttreatment HCV-PCR, matched in age and gender), 84 kidney transplant recipients (KTRs) under mycophenolate and 158 controls (30 with systemic lupus erythematosus, 37 with rheumatoid arthritis, and 91 healthy blood donors). No patient had anti-RR antibody before IFN- $\alpha$ /ribavirin therapy, while 27 (19\%) developed the anti-RR pattern under treatment. The anti-RR antibody was absent in all KTRs and the 158 controls. The frequency of anti-RR antibody was significantly higher in G1 (27; 36.48\%) than in $\mathrm{G} 2(0), p<0.001$. Moreover, and in G1, anti-RR antibody was more frequent in nonresponders (NR) patients $(23,56.1 \%)$ than in relapsers $(\mathrm{REL})(4,12.1 \%) ; p<0.001, \mathrm{OR}[95 \% \mathrm{CI}]=9.26$ [2.75-31.18]. Moreover, anti-RR antibody titer was significantly higher in NR patients $(3,200[1,600-6,400])$ comparatively to REL patients $(800$ [500-1,400]), $p=0.002$. Likewise, log of viral load postribavirin therapy was significantly higher in anti-RR positive patients $(6.24 \pm 0.64)$ than in anti-RR negative $(4.69 \pm 1.06), p<0.001$. Based on these findings, ribavirin-induced anti-RR autoantibody seems to be associated with a more frequent nonresponse to IFN- $\alpha$ /ribavirin therapy with a significant higher HCV viral load.
\end{abstract}

Keywords: hepatitis $\mathrm{C}$, hepatitis $\mathrm{C}$ virus, ribavirin, autoantibody, Rods and Rings

\section{Introduction}

$\mathbf{C}$ HRONIC HePatitis C virus (HCV) infection has been associated with a higher risk of autoantibodies production (23). Anti-smooth muscle (SMA) and antinuclear antibodies (ANA) are the most frequent noticed autoantibodies during HCV infection (23). However, some other autoantibodies such as anti-LKM, ANCA, thyroid autoantibodies, and so on may less frequently occur in HCV patients $(19,21)$. $\mathrm{HCV}$ enters liver cells using the CD81 receptor (2), which is part of the B cell coactivator complex, CD19-CD21-CD81. Therefore, binding with the B cell CD81 receptor might explain, in part, the wide range of autoantibodies that occur in chronic HCV infection.
Despite the recent advances in HCV infection therapy with the availability of new highly efficient anti-HCV drugs, the standard treatment remains in the association of IFN- $\alpha$ and ribavirin in most parts of the world. While the IFN $-\alpha$ is endowed with a nonspecific antiviral activity, ribavirin, a guanosine analog, acts as an inhibitor of the inosine- $5^{\prime}-$ monophosphate dehydrogenase (IMPDH), which leads to depletion of GTP required for the viral RNA synthesis (12). This results in inhibition of the viral polymerase along with an increase of lethal mutagenesis (12).

Recently, a novel autoantibody has been first described during HCV infection and characterized by a distinctive cytoplasmic staining in HEp-2 cells referred to as "Rods and Rings" (RR) $(6-8,13,16)$. The RR structures exhibit a

\footnotetext{
${ }^{1}$ Research Laboratory in Immunology of Renal Transplantation and Immunopathology (LR03SP01), Charles Nicolle Hospital, Tunis El Manar University, Tunis, Tunisia.

${ }^{2}$ Department of Gastro-Entero-Hepatology, Charles Nicolle Hospital, Tunis, Tunisia.

${ }^{3}$ Department of Nephrology and Internal Medicine, Charles Nicolle Hospital, Tunis, Tunisia.
} 


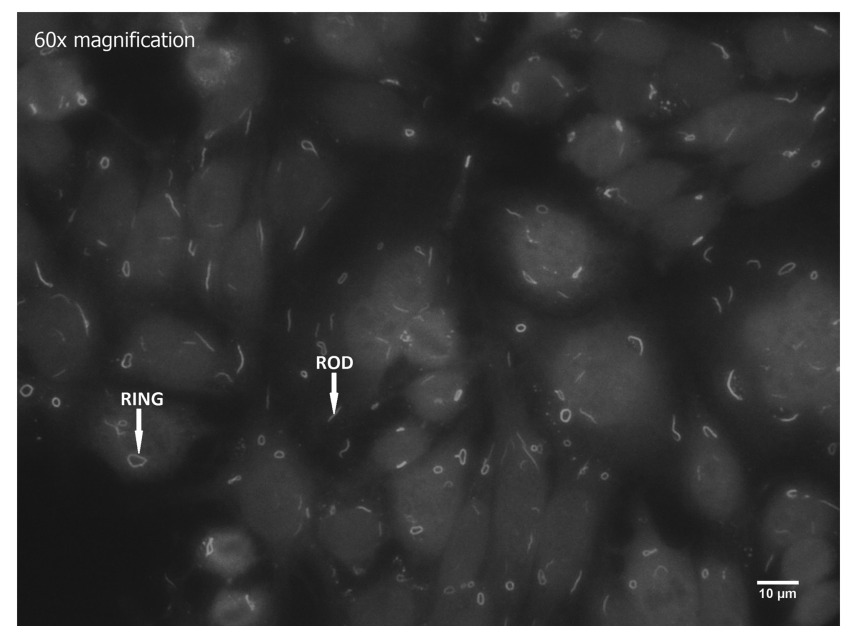

FIG. 1. The anti-RR antibody pattern detected by IIF on HEp-2 cells. RR, Rods and Rings; IIF, indirect immunofluorescence.

typical conformation with both filamentous (Rod) and annular (Ring) patterns (Fig. 1). Interestingly, one of the major associated autoantigens to RR structures which were initially identified is IMPDH, and its inhibition by either ribavirin or mycophenolate was able to cause RR formation (12). Nonetheless, some other RR-inducers have been recently identified, including 5-aminoimidazole-4-carboxamide ribonucleotide and glucose starvation (19).

Since its discovery in 2005 (3), the anti-RR antibody has become a fascinating subject of discussion about its pathogenic role, clinical utility, including both diagnostic and prognostic values and its impact on $\mathrm{HCV}$ infection activity. In treated $\mathrm{HCV}$ patients by IFN- $\alpha$ /ribavirin, the prevalence of anti-RR antibody, detected by indirect immunofluorescence (IIF) assay on HEp-2 cells, varied between $14.1 \%$ and $36 \%$ in previous studies $(6,8,13,16)$. Interestingly, in these studies, the anti-RR pattern was absent before IFN- $\alpha /$ ribavirin therapy, which led many authors to consider this phenomenon as an authentic model of drug-induced autoantibody generation (4). However, the link between anti-RR antibody occurrence and clinical/biological features has not yet been clearly established (12). Moreover, anti-RR antibody detection during $\mathrm{HCV}$ infection was performed in only selected areas of the world; USA (6), Brazil (13), Italy $(6,8,16)$, and Spain (7), mainly; showed differences according to ethnicity without clear explanation.

Thus, the aim of the present study was to investigate the prevalence of anti-RR antibody in Tunisian HCV-infected patients before and after IFN- $\alpha /$ ribavirin treatment in comparison with an $\mathrm{HCV}$-negative control group, including kidney transplant recipients (KTR) under mycophenolate therapy, and to look for a possible impact on HCV activity and disease outcome.

\section{Materials and Methods}

\section{Subjects}

This study included $142 \mathrm{HCV}$-infected patients and 242 HCV-negative subjects.

The $142 \mathrm{HCV}$ patients were retrospectively investigated between 2013 and 2017 in the department of gastro- enterohepatology of Charles Nicolle Hospital in Tunis. All $\mathrm{HCV}$ patients received the standard treatment associating a weekly injection of pegylated IFN $-\alpha$ and a daily oral intake of ribavirin. While $\mathrm{HCV}-1$ and $\mathrm{HCV}-4$ genotype patients were treated for 48 weeks, those carrying HCV-2 and HCV3 genotypes received the treatment for only 24 weeks. Patients were classified in G1 $(n=74)$ as nonresponders (NR) if HCV-RNA was present throughout the treatment and as relapsers (REL) if HCV-RNA became detectable after the completion of the treatment in patients with an initial correct viral response, and in $\mathrm{G} 2(n=68)$ as sustained virological responders (SVR) when the HCV-RNA remained negative 6 months after the end of the standard therapy. Positive patients for HIV or HVB serology and for autoantibodies such as SMA, ANA, or rheumatoid factor were excluded from the HCV-positive group.

The HCV-negative group $(n=242)$ consisted of 84 KTRs under mycophenolate therapy and 158 subjects (30 systemic lupus erythematosus (SLE) patients, 37 rheumatoid arthritis (RA) patients, and 91 healthy blood donors) served as a control group.

The 84 KTRs were retrospectively investigated between 1998 and 2013 in the department of nephrology and internal medicine of the Charles Nicolle Hospital in Tunis. As induction therapy, all KTRs received polyclonal or monoclonal antibodies and prednisolone. Steroids, Tacrolimus or Cyclosporine, and Mycophenolate Mofetil were given as maintenance therapy.

The SLE $(n=30)$ and RA $(n=37)$ patients were diagnosed according to the criteria Committee of the American College of Rheumatology $(1,10)$ and treated by an association of corticosteroids (prednisone) with either antimalarial (hydroxychloroquine) for SLE patients or methotrexate $(n=37,100 \%)$ /anti-TNF $(n=12,32.43 \%)$ therapies for RA patients.

All patients and controls gave written informed consent to participate in the study, and the local Ethics Committee of Charles Nicolle Hospital approved this study. No benefits in any form have been received or will be received from a commercial party related directly or indirectly to the subject of this article.

\section{Blood sampling and HCV antibodies detection}

Serum samples from HCV patients were obtained before the start of the IFN- $\alpha$ /ribavirin treatment, at 24 weeks and 6 months after its completion. HCV antibodies (Ab) were detected by a DIA.PRO ELISA kit (Diagnostic Bioprobes Srl, Milano, Italy) in all HCV patients and controls.

\section{HCV genotyping and quantification}

HCV RNA extraction was performed using the viral NA extraction kit (DiaSorin, Dublin, Ireland) following the manufacturer's instructions.

$\mathrm{HCV}$ genotyping was made by a direct sequencing procedure. First, a reverse transcription PCR (RT-PCR) was performed to obtain cDNA (copy DNA) using extracted RNA and an RT-PCR kit (Promega). Then, an amplification of both $5^{\prime} \mathrm{NC}$ and $\mathrm{NS} 5 \mathrm{~b}$ regions was achieved using the INNO-LiPATM HCV II kit (Innogenetics, Inc., Ghent, Belgium) and the PROLIGO ${ }^{\circledR}$ kit (Sigma-Aldrich Chemie $\mathrm{GmbH}$, Taufkirchen, Germany), respectively. The amplified 
products were purified using the QIAquick Gel extraction kit (Qiagen $\mathrm{GmbH}$, Hilden, Germany) and were sequenced using internal primers for each amplified region $\left(5^{\prime} \mathrm{NC}\right.$ and NS5B) and the ABI Prism ${ }^{\circledR}$ BigDye $^{\mathrm{TM}}$ Terminator Cycle Sequencing Kit (Applied Biosystems, CA). The products were analyzed on an automatic TOWER MICRO-Gene Clipper $^{\mathrm{TM}}$ sequencer, then the obtained sequences were compared to the reference $\mathrm{HCV}$-sequences and HCV genotypes were determined in HCV BLAST site (https://hcv.lanl .gov/content/sequence/BASIC_BLAST/basic_blast.html).

HCV-RNA quantification was performed by a quantitative real-time PCR using the $\operatorname{artus}^{\circledR}$ HCV RG RT-PCR Kit (Qiagen $\mathrm{GmbH}$ ) within the QIAGEN's real-time PCR cycler, the Rotor-Gene $\mathrm{Q}^{\circledR}$ (Qiagen $\mathrm{GmbH}$ ).

\section{IIF on HEp-2 cells}

Serum samples from HCV patients and HCV-negative subjects were analyzed by IIF test using commercial HEp-2010 cells slides (EUROIMMUN Medizinische Labordiagnostika AG, Lübeck, Germany) and following the manufacturer's instructions. Fluorescent images were read by two independent expert observers with a Motic BA310E Trinocular Microscope (Motic, Kowloon, Hong Kong) and then captured using a LED-3002 FC camera (AESKU.SYSTEMS, Wendelsheim, Germany). When positive, anti-RR antibody titer was determined by a twofold serially diluting of serum in PBS.

\section{Statistical analysis}

Statistical evaluation was carried out using the Statistical Package for the Social Sciences (SPSS) version $11\left(\right.$ IBM $^{\circledR}$, Armonk). $p$-values $<0.05$ were considered significant.
Chi-square or Fisher exact tests were used to test the association between categorical variables. Odds ratio (OR) together with $95 \%$ confidence intervals $[95 \% \mathrm{CI}]$ were calculated to estimate the strength of the association.

To assess the Gaussian distribution of quantitative and semiquantitative variables, histograms were built together with the analysis of skewness and kurtosis.

ANOVA, Mann-Whitney $U$ and Kruskal-Wallis tests were used to analyze quantitative and semiquantitative variables, as appropriate.

Correlations between quantitative variables were assessed by Pearson or Spearman correlation coefficients, as appropriate.

\section{Results}

In total, $142 \mathrm{HCV}$ patients and $242 \mathrm{HCV}$-negative subjects (84 KTRs +158 controls) were included (Table 1). Mean age was at $46.73 \pm 19.96$ years for $\mathrm{HCV}$ patients, $32.37 \pm 12.12$ years for the KTRs group, and 46.7 \pm 13.05 years for the controls. The sex ratio (Men/Women) was 0.84 (65/77) for the HCV-positive group, 1.4 (49/35) for KTRs patients, and $0.37(43 / 115)$ for the control group. The HCV antibody serology was positive for all $\mathrm{HCV}$ patients and negative in all subjects of the two other groups.

$\mathrm{HCV}$ genotypes frequencies was as following: HCV-1a $n=5 \quad(3.5 \%), \mathrm{HCV}-1 \mathrm{~b} \quad n=104(73.2 \%), \mathrm{HCV}-2 \quad n=15$ (10.6\%), HCV-3 $n=2$ (1.4\%), and HCV-4 $n=16$ (11.3\%). Log of the pretreatment HCV load was at 5.99 \pm 0.58 , while it significantly decreased to $3.22 \pm 2.3$ in the sixth month of posttreatment period, $p=7.3 \mathrm{E}-30$. Mean duration of IFN- $\alpha$ / ribavirin therapy was $45.13 \pm 7.81$ weeks. Forty-one $(28.9 \%)$

Table 1. Clinical and Biological Features of Hepatitis C Virus Patients, Kidney Transplant Recipients, and CONTROLS

\begin{tabular}{|c|c|c|c|}
\hline & $H C V$ patients $\mathrm{n}=142$ & KTRs $\mathrm{n}=84$ & Controls $\mathrm{n}=158$ \\
\hline Sex ratio $(M / F)$ & $0.84(65 / 77)$ & $1.4(49 / 35)$ & $0.37(43 / 115)$ \\
\hline Mean age $\pm S D$ (years) & $46.73 \pm 11.96$ & $32.37 \pm 12.12$ & $46.7 \pm 13.05$ \\
\hline Anti-HCV antibody & $142(100 \%)$ & 0 & 0 \\
\hline \multicolumn{4}{|l|}{ HCV genotypes } \\
\hline Genotype 1a & $5(3.5 \%)$ & - & - \\
\hline Genotype $1 \mathrm{~b}$ & $104(73.2 \%)$ & - & - \\
\hline Genotype 2 & $15(10.6 \%)$ & - & - \\
\hline Genotype 3 & $2(1.4 \%)$ & - & - \\
\hline Genotype 4 & $16(11.3 \%)$ & - & - \\
\hline Log PreT HCV load mean \pm SD & $5.99 \pm 0.58$ & - & - \\
\hline Log PostT HCV load mean \pm SD & $3.22 \pm 2.3$ & - & - \\
\hline IFN- $\alpha /$ ribavirin duration (weeks) & $45.13 \pm 7.81$ & - & - \\
\hline \multicolumn{4}{|l|}{ HCV infection outcome } \\
\hline SVR & $68(47.9 \%)$ & - & - \\
\hline REL & $33(23.2 \%)$ & - & - \\
\hline NR & $41(28.9 \%)$ & - & - \\
\hline Steroids & - & $84(100 \%)$ & $67(43.4 \%)$ \\
\hline Mycophenolate & - & $84(100 \%)$ & - \\
\hline Tacrolimus & - & $47(55.9 \%)$ & - \\
\hline Azathioprine & - & $47(55.9 \%)$ & - \\
\hline Ciclosporin & - & $1(1.2 \%)$ & - \\
\hline Antimalarial & - & - & $30(19 \%)$ \\
\hline Methotrexate & - & - & $37(23.4 \%)$ \\
\hline Anti-TNF & - & - & $12(7.6 \%)$ \\
\hline
\end{tabular}

PreT, pretreatment (IFN- $\alpha$ /ribavirin); PostT, posttreatment; SVR, sustained virological response; REL, relapsers; NR, nonresponders; $\mathrm{HCV}$, hepatitis C virus; KTR, kidney transplant recipient. 
Table 2. Comparative Analysis of G1 and G2 Groups

\begin{tabular}{|c|c|c|c|}
\hline$H C V$ patients $\mathrm{n}=142$ & $G 1 \mathrm{n}=74$ & $G 2 \mathrm{n}=68$ & $\mathrm{p}$ \\
\hline Sex ratio $(\mathrm{M} / \mathrm{F})$ & $0.85(34 / 40)$ & $0.83(31 / 37)$ & 0.966 \\
\hline Mean age \pm SD (years) & $48.55 \pm 12.63$ & $44.74 \pm 10.93$ & 0.057 \\
\hline \multicolumn{4}{|l|}{$\mathrm{HCV}$ genotypes } \\
\hline Genotype 1a & $2(2.7 \%)$ & $3(4.4 \%)$ & \multirow[t]{5}{*}{0.96} \\
\hline Genotype $1 \mathrm{~b}$ & $56(75.7 \%)$ & $48(70.6 \%)$ & \\
\hline Genotype 2 & $7(9.5 \%)$ & $8(11.8 \%)$ & \\
\hline Genotype 3 & $1(1.4 \%)$ & $1(1.5 \%)$ & \\
\hline Genotype 4 & $8(10.8 \%)$ & $8(11.8 \%)$ & \\
\hline Log PreT HCV load mean \pm SD & $6.04 \pm 0.54$ & $5.93 \pm 0.62$ & 0.273 \\
\hline Log PostT HCV load mean $\pm S D$ & $5.26 \pm 1.19$ & 1 & $<0.001$ \\
\hline IFN- $\alpha /$ ribavirin duration (weeks) & $45.41 \pm 7.5$ & $44.82 \pm 8.19$ & 0.659 \\
\hline \multicolumn{4}{|l|}{ HCV infection outcome } \\
\hline SVR & 0 & $68(100 \%)$ & - \\
\hline REL & $33(44.6 \%)$ & 0 & - \\
\hline NR & $41(55.4 \%)$ & 0 & - \\
\hline
\end{tabular}

HCV patients had positive HCV-RNA throughout the treatment and were classified as NR, while 33 (23.2\%) were classified as REL. NR and REL HCV-patients were grouped in G1, while the 68 (47.9\%) SVR patients were classified in G2.

\section{Comparative analysis of G1 and G2 groups}

G1 $(\mathrm{REL}+\mathrm{NR})$ and G2 (SVR) patients were comparable in age and gender; $p=0.966$ and $p=0.057$, respectively (Table 2). There were no significant differences in HCV genotypes frequencies between G1 and G2 patients, $p=0.96$. Moreover, no statistical difference was noted in mean log of pretreatment viral load between G1 (6.04 \pm 0.54$)$ and G2 $(5.93 \pm 0.62), p=0.273$. Mean IFN- $\alpha /$ ribavirin treatment duration was similar in G1 (45.41 \pm 7.5 weeks) and in G2 (44.82 \pm 8.19 months), $p=0.659$.

\section{Anti-RR antibody in HCV patients and $\mathrm{HCV}$-negative subjects}

Anti-RR antibody was negative in all HCV patients before induction of IFN- $\alpha$ /ribavirin therapy, in KTRs under mycophenolate and in controls. Anti-RR antibody appeared in $27(19 \%) \mathrm{HCV}$-treated patients in the posttreatment period. Median [1st-3rd quartiles] of anti-RR antibody titer in HCV patients was 3,200 [1,600-6,400].
Analytic results showed no significant association between anti-RR antibody and either gender or age; $p=0.877$ and $p=0.55$, respectively (Table 3 ). Interestingly, anti-RR antibody was positive in only patients carrying $\mathrm{HCV}-1 \mathrm{~b}$ or $\mathrm{HCV}-4$ genotypes, but the differences failed to reach significance, $p=0.186$. Mean IFN- $\alpha /$ ribavirin therapy duration was significantly higher in HCV-patients with anti-RR antibody (48 vs. $44.45 \pm 8.5$ weeks), $p=0.033$.

Besides, anti-RR antibody was significantly more frequent in G1 $(27,36.48 \%)$ than in G2 (0), $p<0.001$. Moreover, mean posttreatment log of HCV load was significantly higher in anti-RR-positive patients $(6.24 \pm 0.65)$ comparatively to those with negative anti-RR $(2.51 \pm 1.94)$, $p<0.001$. Likewise, there was a significant correlation between anti-RR antibody titer and the posttreatment log of HCV load, Spearman rho $=0.677, p<0.001$.

\section{Anti-RR antibody analysis in G1}

In G1, anti-RR antibody was significantly associated to posttreatment HCV load $(6.24 \pm 0.64$ vs. $4.69 \pm 1.06)$ and therapy duration (48 vs. $43.91 \pm 9.11$ weeks); $p<0.001$ and $p=0.023$, respectively (Table 4 ). Besides, the frequency of anti-RR antibody was significantly higher in NR patients

Table 3. Analysis of Anti-Rods and Rings Antibody in Hepatitis C Virus Patients

\begin{tabular}{lccc}
\hline$H C V$-patients $\mathrm{n}=142$ & Anti-RR $A b+\mathrm{n}=27$ & Anti-RR Ab-n=115 & $\mathrm{p}$ \\
\hline Sex ratio (M/F) & $12 / 15(0.8)$ & $0.85(53 / 62)$ & 0.877 \\
Mean age \pm SD (years) & $45.48 \pm 11.87$ & $47.02 \pm 12.08$ & 0.55 \\
HCV genotypes & 0 & $5(4.3 \%)$ & 0.186 \\
Genotype 1a & $23(85.2 \%)$ & $81(70.4 \%)$ & \\
Genotype 1b & 0 & $15(13 \%)$ & \\
Genotype 2 & 0 & $2(1.7 \%)$ & $<0.001$ \\
Genotype 3 & $4(14.8 \%)$ & $12(10.4 \%)$ & 0.033 \\
Genotype 4 & $6.24 \pm 0.65$ & $2.51 \pm 1.94$ & $<0.001$ \\
Log PostT HCV load mean \pm SD & 48 & $44.45 \pm 8.5$ & \\
IFN- $\alpha /$ ribavirin duration (weeks) & $27(36.48 \%)$ & $47(63.52 \%)$ & \\
HCV-patients groups & 0 & $68(100 \%)$ & \\
G1 $(n=74)$ & & & \\
G2 $(n=68)$ & & & \\
\hline
\end{tabular}


Table 4. Analysis of Anti-Rods and Rings Antibody in G1

\begin{tabular}{lccr}
\hline$G 1 \mathrm{n}=74$ & Anti-RR $A b+\mathrm{n}=27$ & Anti-RR $A b-\mathrm{n}=47$ & $\mathrm{p}$ \\
\hline Sex ratio (M/F) & $0.8(12 / 15)$ & $0.88(22 / 25)$ & 0.844 \\
Mean age \pm SD (years) & $45.48 \pm 11.87$ & $50.32 \pm 0.49$ & 0.113 \\
HCV genotypes & 0 & $2(4.3 \%)$ & 0.142 \\
Genotype 1a & $23(85.2 \%)$ & $33(70.2 \%)$ & \\
Genotype 1b & 0 & $7(14.9 \%)$ & \\
Genotype 2 & 0 & $1(2.1 \%)$ & \\
Genotype 3 & $4(14.8 \%)$ & $4(14.8 \%)$ & $<0.001$ \\
Genotype 4 & $6.24 \pm 0.65$ & $4.69 \pm 1.06$ & 0.023 \\
Log PostT HCV load mean \pm SD & 48 & $43.91 \pm 9.11$ & $<0.001$ \\
IFN- $\alpha /$ ribavirin duration (weeks) & $4(12.1 \%)$ & $29(87.9 \%)$ & \\
HCV-infection outcome & $23(56.1 \%)$ & $18(43.9 \%)$ & \\
REL $n=33$ & & & \\
NR $n=41$ & & & \\
\hline
\end{tabular}

RR, Rods and Rings.

$(23,56.1 \%)$ than in REL patients $(4,12.1 \%) ; p<0.001$, OR $[95 \% \mathrm{CI}]=9.26$ [2.75-31.18] (Table 4). Moreover, anti-RR antibody titer was significantly higher in NR patients $(3,200$ [1,600-6,400]) comparatively to REL patients (800 [5001,400]), $p=0.002$ (Fig. 2).

\section{Discussion}

The immune system has a critical capacity for preventing responses against self-antigens through diverse central and peripheral mechanisms of tolerance. Therefore, appearance of autoantibodies is the consequence of a failure or a breakdown of both $\mathrm{B}$ cell and $\mathrm{T}$ cell tolerance. Among factors that trigger autoimmunity and autoantibody generation, mimicry with infectious pathogens antigens, polyclonal activation of $\mathrm{B}$ cells, and drugs intake are well recognized. Actually, during chronic $\mathrm{HCV}$ infection, there is often a polyclonal activation of B cells, which is associated with cryoglobulinemia and various autoantoantibodies (18). Besides, of all

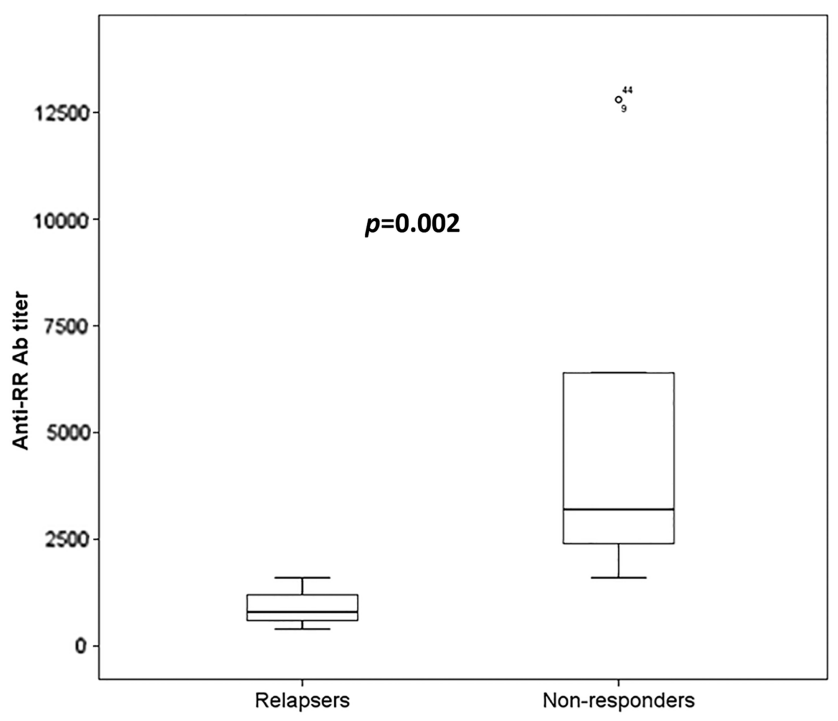

FIG. 2. Box plots showing a significantly higher titer of anti-RR antibody in nonresponder patients comparatively to relapse patients. the noninfectious environmental exposures associated with autoimmunity, drugs are the best recognized and most often reported $(9,22)$. The most commonly recognized drugrelated syndromes are lupus-like disorders which are characterized by autoantibodies to histones and single-stranded DNA, rather than autoantibodies to double-stranded DNA as are found more often in nondrug-related lupus (9). Likewise, the recently described anti-RR antibody has been presented as a unique model of drug-induced antibody generation during treated HCV infection by IFN- $\alpha$ /ribavirin therapy (4). Nevertheless, its utility in clinical practice remains to be determined.

In this study, no HCV patients had anti-RR antibody before the beginning of the IFN- $\alpha$ /ribavirin therapy. This result corroborates those of the mainstream of published studies, in which no treatment-naive HCV patient showed anti-RR activity $(8,13,16)$. Moreover, 27 (19\%) treated HCV patients became reactive to RR structures, while the 84 KTRs under mycophenolate and the 158 controls did not show any anti-RR activity. This result highlights the direct role of IFN- $\alpha$ /ribavirin in anti-RR antibody induction in our $\mathrm{HCV}$ patients as suggested by the anti-RR absence before treatment. Likewise, previous studies showed the link between HCV traditional treatment and appearance of anti-RR reactivity in about $14 \%$ to $36 \%$ of patients $(6,8,13,16)$. However, some other studies reported that anti-RR antibody can very seldom occur in HCV-negative subjects $(8,13,20)$. In fact, Keppeke et al. (13) reported an anti-RR activity in one patient with HVB infection, Climent et al. (7) showed the presence of anti-RR antibody in 14 patients with autoimmune diseases, and Shaikh et al. (20) estimated the prevalence of this autoantibody among the general population at $0.823 \%$. Nevertheless, and according to the most of previous reports and the present study, the anti-RR reactivity is primarily the consequence of IFN- $\alpha$ /ribavirin therapy. In fact, it has been reported that the inhibition of IMPDH by ribavirin is a major risk factor for anti-RR generation (12). Moreover, IIF on HEK293 cells expressing IMPDH (17) and sandwich ELISA using an anti-IMPDH capture antibody (15) recognized the IMPDH as the major target of anti-RR antibodies in positive sera. Hence, it would be valuable to test IMPDH reactivity in our anti-RR antibody positive sera. 
Besides, inhibition of IMPDH by mycophenolic acid has been reported to induce its aggregation into RR structures $(11,12)$. Proliferating cells such as activated immune cells and cancer cells highly express IMPDH (12). Thus, IMPDH is a potential target for immunosuppressive drugs such as mycophenolate (12) for prevention of organ transplant rejection and in some cases for lupus nephritis treatment. In the present study, none of the 84 KTRs under mycophenolate therapy developed anti-RR activity. Interestingly, no study reported anti-RR occurrence in patients under mycophenolate treatment (4). The fact that IMPDH2 inhibition by ribavirin and mycophenolate induces RR formation, but only ribavirin therapy has been associated with anti-RR reactivity is at least intriguing. The peculiar absence of antiRR antibodies in KTRs under mycophenolate can be explained by the highly immunosuppressed status, which could inhibit autoantibody generation. Inversely, and during $\mathrm{HCV}$-infection, $\mathrm{HCV}$ has been reported to trigger autoimmunity and could render aggregated IMPDH more immunogenic.

In this study, anti-RR antibody was negative in all of the 158 control subjects. The control group consisted of 67 patients with an autoimmune condition (SLE or RA) and 91 healthy blood donors. None of the SLE/RA patients received an anti-IMPDH2 treatment. It is of note that the $37(100 \%)$ RA patients received methotrexate therapy. Methotrexate has been shown to induce RR structure formation in cultured cells (5) as well as in PBMCs of patients taking methotrexate (14). Thus, either the autoimmune background or the methotrexate therapy did not seem to be sufficient to induce anti-RR antibody generation. Nonetheless, as mentioned above, some studies reported a rare anti-RR detection during autoimmune disease (7) or in healthy subjects (20). Therefore, a prospective study in a larger cohort of patients and healthy subjects is needed to determine the exact prevalence of anti-RR activity in autoimmune diseases and in the general population.

In the present study, we noted that anti-RR antibody appeared after IFN- $\alpha$ /ribavirin therapy only in nonresponders and REL patients, while HCV-patients with sustained virological response stayed negative, $p<0.001$. Moreover, NR patients had more frequently anti-RR activity with significantly higher titers comparatively to REL; $p<0.001$, OR $[95 \% \mathrm{CI}]=9.26[2.75-31.18]$ and $p=0.002$. Remarkably, these findings corroborate, in part, results of previous reports $(6,8,16)$. In fact, Covini et al. (8) and Novembrino et al. (16) reported a significant higher prevalence in REL patients, while Carcamo et al. (6) showed that REL patients had significant higher titers of anti-RR antibody. It is of note that REL usually receive a second and sometimes a third round of IFN- $\alpha$ /ribavirin therapy (12). Thus, a longer exposure to the treatment may increase the risk of anti-RR antibody generation. Interestingly, in this study, we showed a significant association between IFN-/ribavirin treatment duration and anti-RR antibody frequency, $p=0.033$. Moreover, Novembrino et al. (16) reported an increase of anti-RR antibody frequency depending on therapy duration.

In this study, we also noted significant associations of posttreatment HCV load with on one hand the frequency of anti-RR activity and on the other hand anti-RR antibody titer; $p<0.001$ and $p<0.001$, respectively. However, in one study (13), no association between anti-RR antibody and viral load has been reported. Thus, association between viral load and anti-RR antibody frequency and titer needs to be investigated in larger and independent cohorts. Nonetheless, our findings give a clue as for the close interaction between the immune system and HCV. The failure of the therapy allows continued presence of the virus for extended periods of time. This long-term presence of the virus, coupled with the ribavirin inducing the assembly of IMPDH into rods and rings, could trigger an alteration in the immunogenicity of IMPDH over time, leading to autoantibody production. This could explain the higher prevalence of anti-RR antibody in REL and nonresponder patients.

\section{Conclusion}

Based on these findings, ribavirin-induced anti-RR autoantibody seems to be associated with a more frequent nonresponse to IFN- $\alpha$ /ribavirin therapy with a significant higher HCV viral load.

\section{Acknowledgment}

This study was granted and supported by the Research Laboratory in Immunology of Renal Transplantation and Immunopathology (LR03SP01), Charles Nicolle Hospital, Tunis El Manar University, Tunisia.

\section{Author Disclosure Statement}

No benefits in any form have been received or will be received from a commercial party related directly or indirectly to the subject of this article.

\section{Authors' Contributions}

Y.G. proposed the study. T.D. and S.A. realized all the practical parts of the study. T.D., I.S., L.M., and T.B.A. analyzed the data. T.D. wrote the original draft. All authors contributed to the design of the study. Y.G. is the guarantor of the integrity of this study. J.A., M.J., and M.M. had the same contribution.

\section{References}

1. Arnett FC, Edworthy SM, Bloch DA, et al. The American Rheumatism Association 1987 revised criteria for the classification of rheumatoid arthritis. Arthritis Rheum 1988;31: 315-324.

2. Bruening J, Lasswitz L, Banse $\mathrm{P}$, et al. Hepatitis $\mathrm{C}$ virus enters liver cells using the CD81 receptor complex proteins calpain-5 and CBLB. PLoS Pathog 2018;14:e1007111.

3. Calise SJ, Carcamo WC, Ceribelli A, et al. Antibodies to rods and rings. In: Shoenfeld Y, Meroni PL, Gershwin ME, eds. Autoantibodies. 3rd Ed. Elsevier, ScienceDirect, Cambridge, MA. 2013:161-167.

4. Calise SJ, Keppeke GD, Andrade LEC, et al. Anti-rods/ rings: a human model of drug-induced autoantibody generation. Front Immunol 2015;6:41.

5. Calise SJ, Purich DL, Nguyen T, et al. 'Rod and ring' formation from IMP dehydrogenase is regulated through the one-carbon metabolic pathway. J Cell Sci 2016;129: 3042-3052.

6. Carcamo WC, Ceribelli A, Calise SJ, et al. Differential reactivity to IMPDH2 by anti-rods/rings autoantibodies and 
unresponsiveness to pegylated interferon-alpha/ribavirin therapy in US and Italian HCV patients. J Clin Immunol 2013;33:420-426.

7. Climent J, Morandeira F, Castellote J, et al. Clinical correlates of the « rods and rings » antinuclear antibody pattern. Autoimmunity 2016;49:102-108.

8. Covini G, Carcamo WC, Bredi E, et al. Cytoplasmic rods and rings autoantibodies developed during pegylated interferon and ribavirin therapy in patients with chronic hepatitis C. Antivir Ther 2012;17:805-811.

9. Dedeoglu F. Drug-induced autoimmunity. Curr Opin Rheumatol 2009;21:547-551.

10. Hochberg MC. Updating the American College of Rheumatology revised criteria for the classification of systemic lupus erythematosus. Arthritis Rheum 1997,40:1725.

11. Ji Y, Gu J, Makhov AM, et al. Regulation of the interaction of inosine monophosphate dehydrogenase with mycophenolic acid by GTP. J Biol Chem 2006;281:206-212.

12. Keppeke GD, Calise SJ, Chan EKL, et al. Anti-rods/rings autoantibody generation in hepatitis $\mathrm{C}$ patients during interferon- $\alpha$ /ribavirin therapy. World J Gastroenterol 2016; 22:1966-1974.

13. Keppeke GD, Nunes E, Gomes Ferraz ML, et al. Longitudinal study of a human drug-induced model of antibody to cytoplasmic Rods/Rings following HCV therapy with ribavirin and interferon- $\alpha$. PLoS One 2012;7:e45392.

14. Keppeke GD, Prado MS, Nunes E, et al. Differential capacity of therapeutic drugs to induce Rods/Rings structures in vitro and in vivo and generation of anti-Rods/Rings autoantibodies. Clin Immunol 2016;173:149-156.

15. Keppeke GD, Satoh M, Ferraz ML, et al. Temporal evolution of human autoantibody response to cytoplasmic rods and rings structure during anti-HCV therapy with ribavirin and interferon- $\alpha$. Immunol Res 2014;60:38-49.

16. Novembrino C, Aghemo A, Ferraris Fusarini C, et al. Interferon-ribavirin therapy induces serum antibodies determining 'rods and rings' pattern in hepatitis $\mathrm{C}$ patients. J Viral Hepat 2014;21:944-949.
17. Probst C, Radzimski C, Blöcker IM, et al. Development of a recombinant cell-based indirect immunofluorescence assay (RC-IFA) for the determination of autoantibodies against "rings and rods"-associated inosine- 5 '-monophosphate dehydrogenase 2 in viral hepatitis C. Clin Chim Acta 2013; 418:91-96.

18. Schiavinato A, Zanetto A, Pantano G, et al. Polyclonal and monoclonal B lymphocytes response in HCV-infected patients treated with direct-acting antiviral agents. J Viral Hepat 2017;24:1168-1176.

19. Schiavone CR, Griffin ME, Pirozzi M, et al. Compositional complexity of rods and rings. Mol Biol Cell 2018;29:23032316.

20. Shaikh Y, Krantz A, and El-Farra Y. Anti-rods and rings autoantibodies can occur in the hepatitis C-naïve population. J Prev Med Hyg 2013;54:175-180.

21. Tran A, Quaranta JF, Benzaken S, et al. High prevalence of thyroid autoantibodies in a prospective series of patients with chronic hepatitis $\mathrm{C}$ before interferon therapy. Hepatology $1993 ; 18: 253-257$.

22. Uetrecht J. Current trends in drug-induced autoimmunity. Autoimmun Rev 2005;4:309-314.

23. Williams MJ, Lawson A, Neal KR, et al. Autoantibodies in chronic $\mathrm{C}$ virus infection and their association with disease profile. J Viral Hepat 2009;16:325-331.

Address correspondence to:

Dr. Tarak Dhaouadi

Research Laboratory in Immunology of Renal

Transplantation and Immunopathology (LRO3SP01)

Charles Nicolle Hospital

Tunis El Manar University

Bd 9 Avril

Tunis 1006

Tunisia

E-mail: dhaouaditarak@yahoo.fr 